Supplement of Nat. Hazards Earth Syst. Sci., 18, 419-427, 2018

https://doi.org/10.5194/nhess-18-419-2018-supplement

(c) Author(s) 2018. This work is distributed under

the Creative Commons Attribution 4.0 License.

(c) (1)

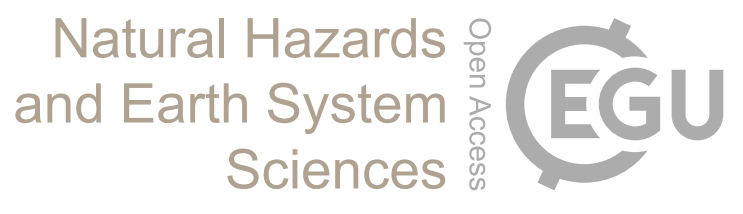

Supplement of

\title{
Brief Communication: Synoptic-scale differences between Sundowner and Santa Ana wind regimes in the Santa Ynez Mountains, California
}

Benjamin J. Hatchett et al.

Correspondence to: Benjamin J. Hatchett (benjamin.hatchett@gmail.com)

The copyright of individual parts of the supplement might differ from the CC BY 4.0 License. 


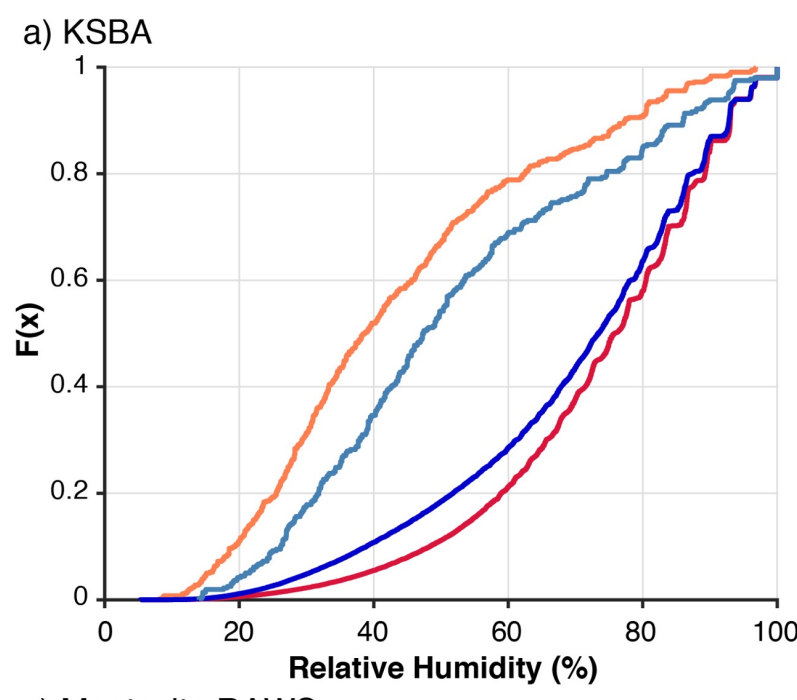

b) KSBA
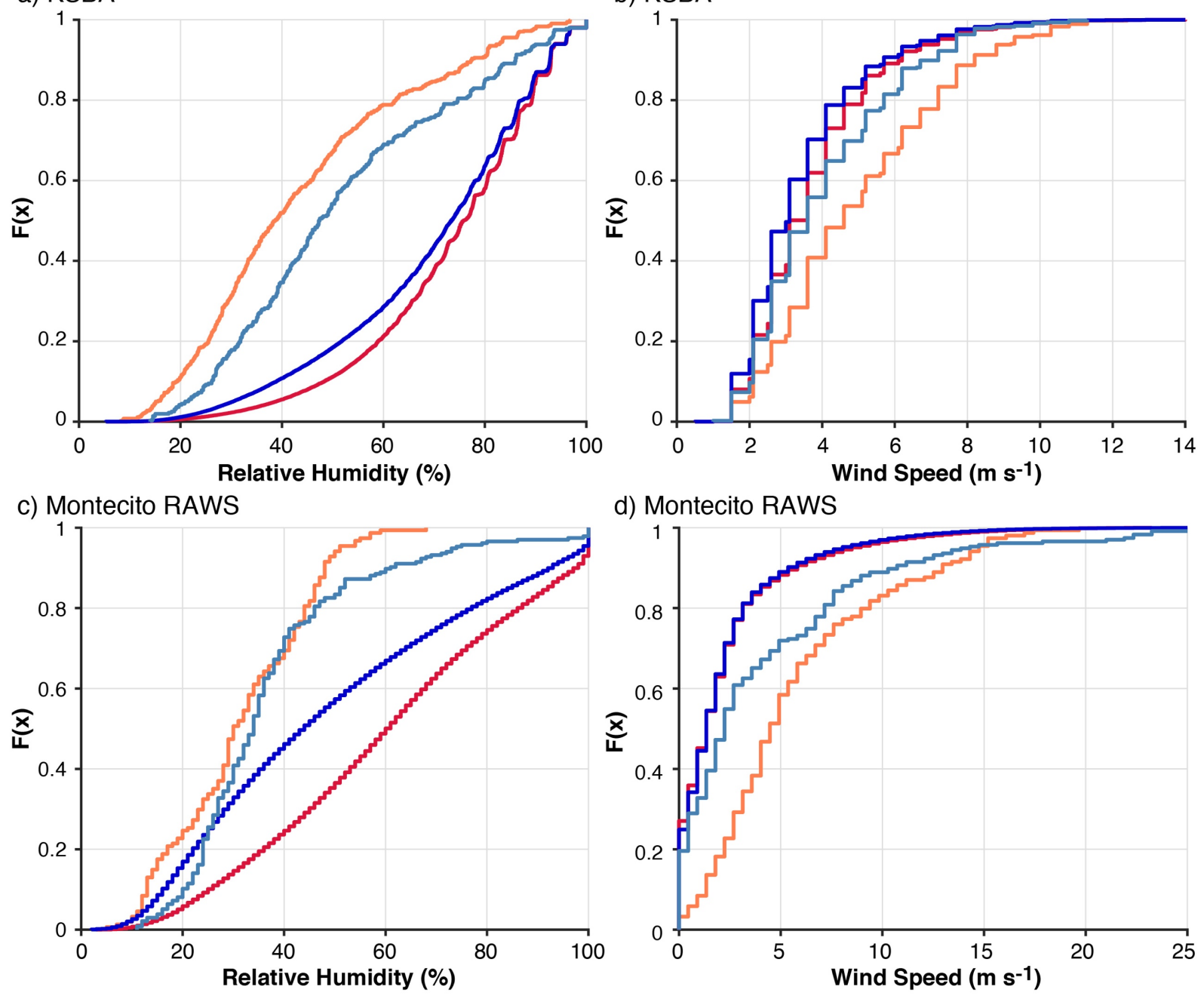

d) Montecito RAWS
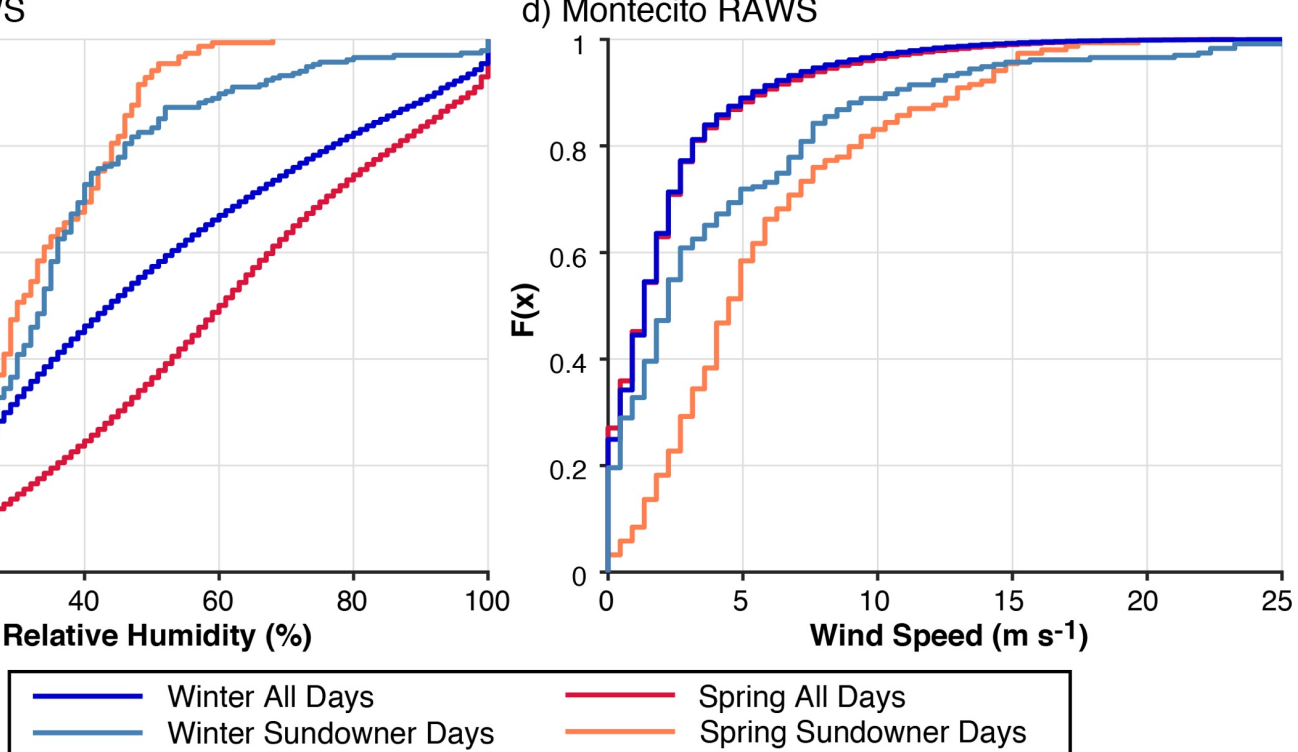

$$
\begin{aligned}
& \text { Spring All Days } \\
& \text { Spring Sundowner Days }
\end{aligned}
$$

Figure S1: (a) Cumulative distributions of relative humidity at KSBA during the extended spring (March-June) Sundowner maxima and extended winter (November-February) Santa Ana maxima. (b) As in (a) except for wind speed at KSBA. (c-d) As in (a-b) but for the Montecito RAWS. Distributions are created from either all hours (All Days) or for the five hours following each identified possible top 0.5\% Sundowner event (Sundowner Days) during the respective peak seasons (see Figure 1d-f). The figure in the main manuscript (Figure 2) uses the period 1997-2014 for KSBA, this figure uses the full period of record (1979-2014) for KSBA. 
a) Nov-Feb

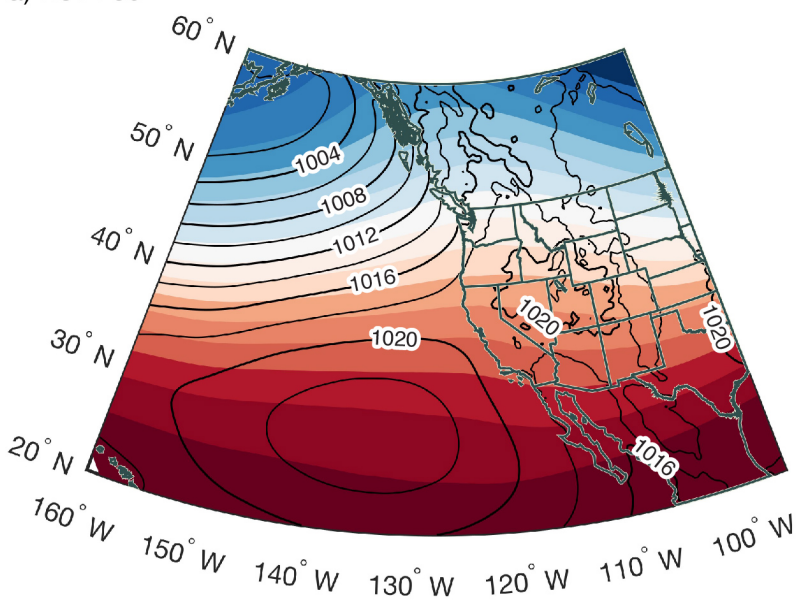

b) Mar-Jun

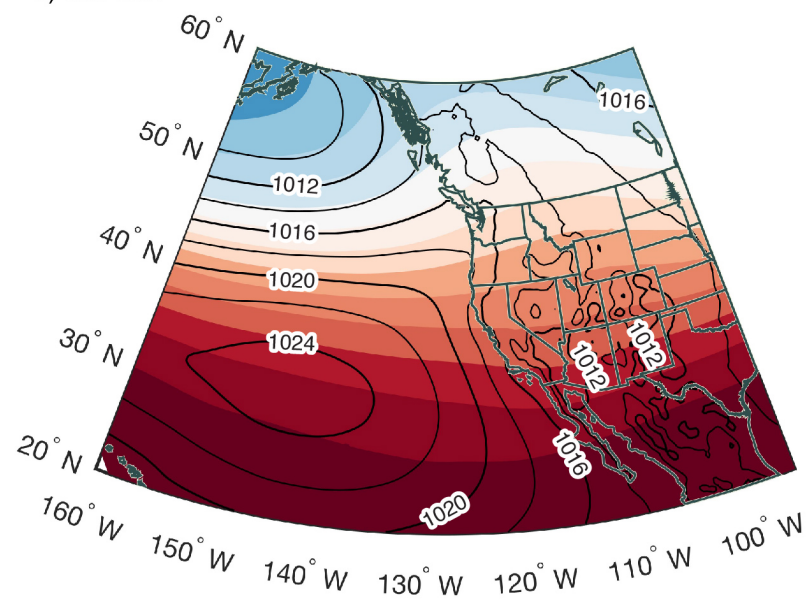

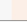

5520

5440 500 hPa Geopotential Height (m)

Figure S2: Seasonal mean $500 \mathrm{hPa}$ geopotential heights (filled contours, contour interval $40 \mathrm{~m}$ ) and sea level pressures (contours every $2 \mathrm{hPa}$, thicker contours show $4 \mathrm{hPa}$ intervals) for extended winter (a) and extended spring (b). 
a) $500 \mathrm{hPa}$ Differences: Nov-Feb

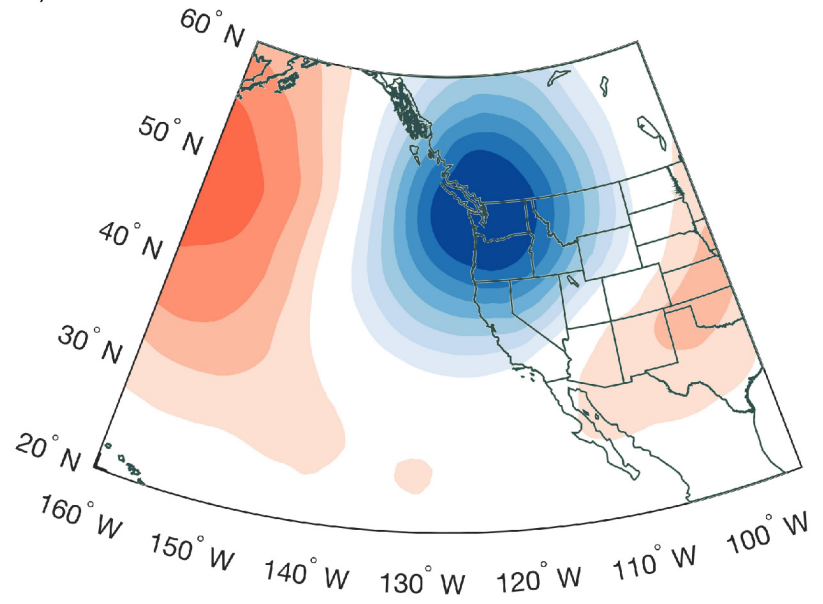

b) $500 \mathrm{hPa}$ Differences:atMar-Jun

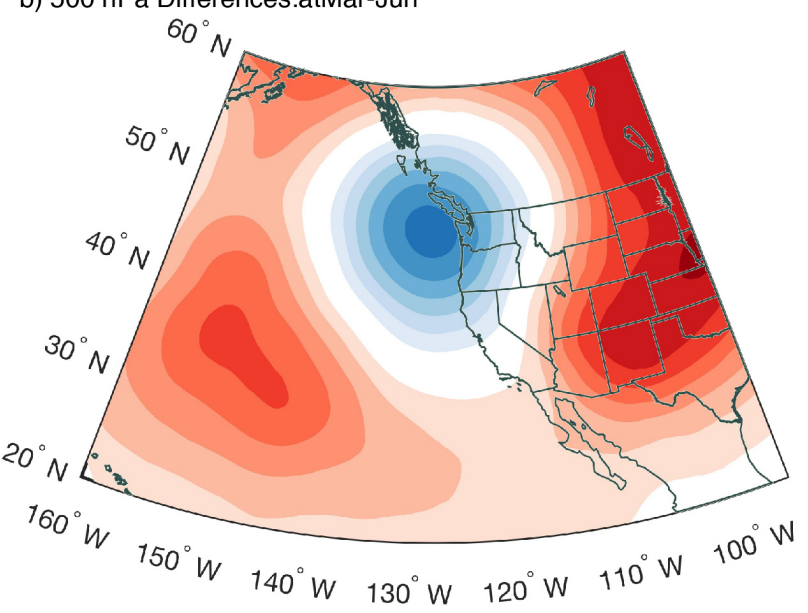

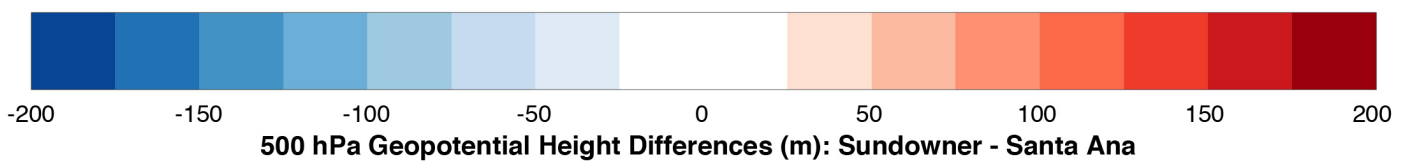

500 hPa Geopotential Height Differences (m): Sundowner - Santa Ana

c) SLP Differences: Nov-Feb

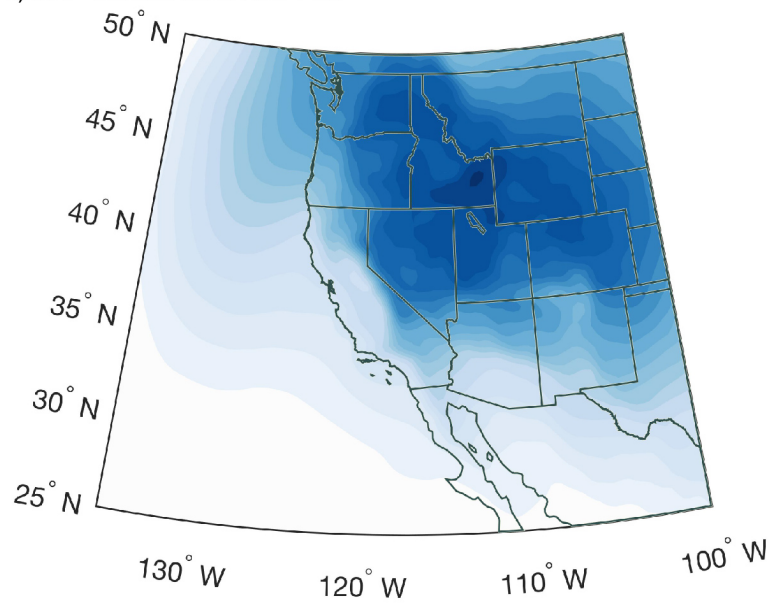

d) SLP Differences:atMar-Jun

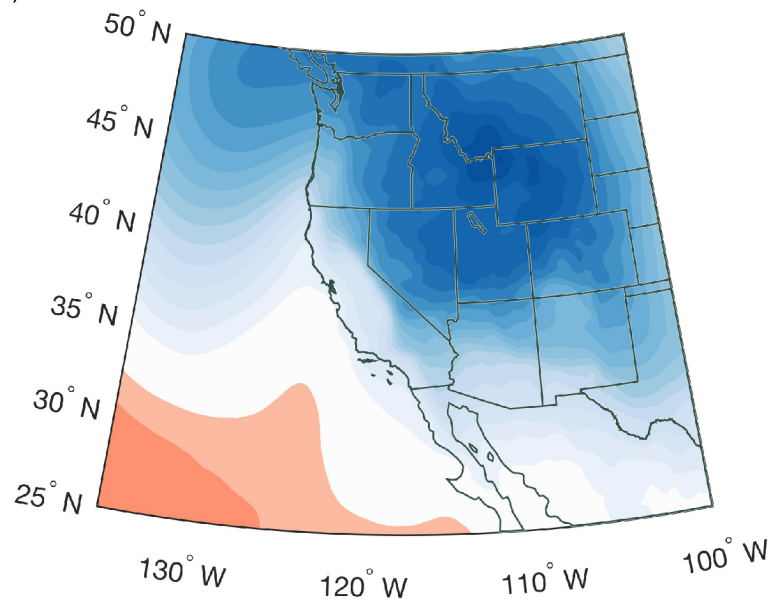

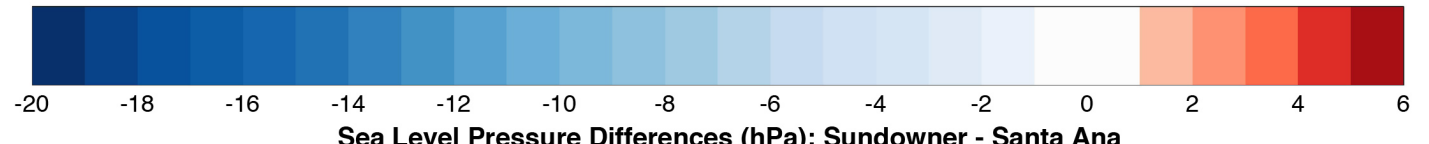

Figure S3: $500 \mathrm{hPa}$ geopotential height differences between Sundowner Events and Santa Ana Only events during extended winter (a) and extended spring (b). Contour interval is $25 \mathrm{~m}$. (c-d) As in (a-b) except for sea level pressure differences. Contour interval is $1 \mathrm{hPa}$. 